Military Technical

College

Kobry Elkobbah, Cairo, Egypt

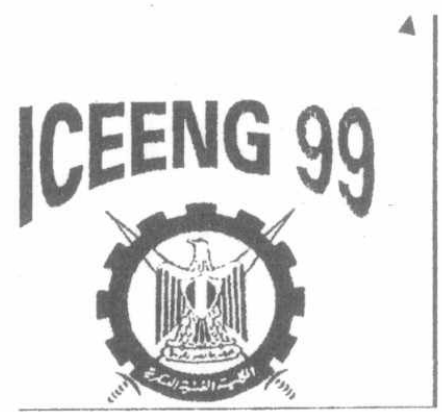

$2^{\text {nd }}$ International Conference on Electrical Engineering ICEENG 99

\title{
Tracking Control of a PM Pancake DC Motor With Fuzzy Logic Technique
}

\author{
F.A.Khalifa** S.Gawish ${ }^{\star \star *}$ M.A.LBadr* A.Kamel ${ }^{\star \star \star *}$
}

\section{Abstract}

This paper introduces a fuzzy logic control ( $F L C$ ) technique for controlling the speed of PM pancake DC motor. In this case the rotor speed of the DC motor follows an arbitrary selected trajectory. The rotor speed is given in a digital form over the control period, under different mechanical loading conditions. These are, constant load, linear load and quadratic load.

The control objective is to achieve accurate trajectory control of the speed, for motors of different parameters and different loading conditions.

Simulation results show that the fuzzy logic controller (FLC) is efficient in speed tracking of DC motors in comparisoin with conventional PI controller.

\section{Keywords}

Fuzzy logic controller(FLC), PM disc type DC motor, PI control, high performance drive system .

Introduction

DC motor drives are widely used in industrial applications such as robotics

*Professor Elec. Eng.Dep.(Ain Shams Univ.)

${ }^{\star \star}$ Professor Elec. Mach. and Power Eng. (MTC)

${ }^{\star \star \star}$ Asist Professor Elec. Mach. and Power Eng. (MTC)

${ }^{\star \star \star \star \star M s c}$. Elec. Mach. and Power Eng. (MTC) 
and electric traction where a wide range of speed and position control is required[1,2]. Robots and manipulators are equipped with servo motors having cylindrical or disc shaped rotors. However, the use of pancake motor with discshaped rotor is predominant in this area today[3] .

An electric drive system is considered "a high performance system" when the rotor position or shaft speed can be made to follow a preselected track at all times. A fast controller is an essential feature of such a drive system.

The objective of a speed controller is to manipulate the terminal voltage in a specified trajectory with minimum deviation $[4,5,6]$.

In many drive applications, the variation of motors and load parameters make the conventional tracking controllers unsatisfactory[4]. Many control techniques have been developed for tracking DC motor [1-7]. However, among of these controllers, fuzzy logic controller (FLC) is an efficient and easy algorithm to control the speed of such high performance DC motors

This paper presents a fuzzy- logic based speed tracking controller for a PM disc type DC motor. Such a controller needs neither nonlinear nor linear mathematical model $[8,9,10,11]$. The influence of the proposed controller on the motor speed trajectory is investigated under three loads to be driven by the motor. These are: constant load, linear load, and quadratic load. Also the robustness of this controller is examined when the DC motor is replaced by another ones, the obtained results are compared with those of a conventional PI controller. The simulated results prove the effectiveness of the proposed fuzzy logic controller in the speed tracking for high performance DC motors.

\section{2-DC Pancake Motor}

The disc motor structure is quite unlike any other motor structure where the internal magnetic field flux is not radial. Instead the flux points parallel to the machine's shaft (called axial direction). The armature is a thin slotless nonmagnetic disk made of ceramic textolit, or aluminum and carrying a printed winding. The printed winding are arranged radially on both sides of the disc. Current in the disc armature winding flow radially, and the disc is placed between two sets of permanent magnets which create axial flux and radial current produces a torque which rotates the rotor as any DC motor. An exploded view of a pancake motor with disc shaped rotor is shown in figure(1) $[12,13]$

Many advantages, in addition to low inertia of the motor with disc armature are reported in [14]. There are:

- No cogging torque (due to the fact that the rotor is nonmagnetic ;

- Large acceleration (due to low rotor inertia ;

- The flux is uniformly distributed in the air gab (due to that the armature is toothless ;

- Low mechanical time constant ; 
- Reduction of the motor mass and overall dimensions ;

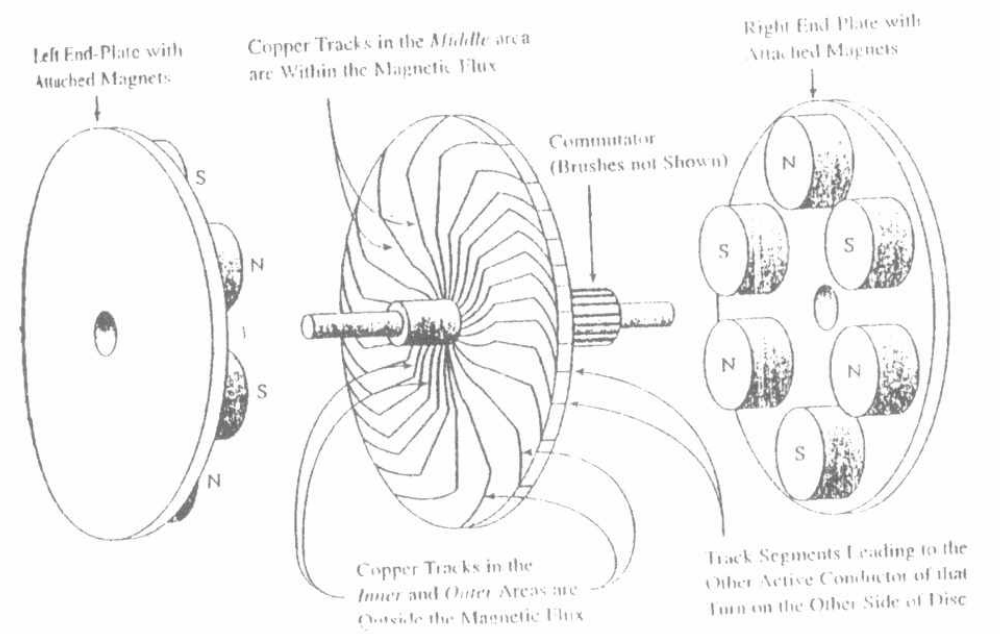

Fig.1. An exploded view of a pancake motor with disc shaped rotor

The equivalent circuit of the pancake motor with disc shaped rotor is identical to that of the separately excited DC motor except that there are no field winding connections[15]. Figure(2) shows the equivalent circuit of this motor .

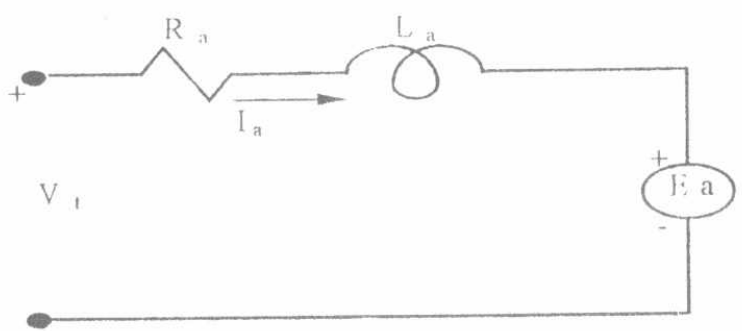

Fig. 2. The equivalent circuit of a pancake DC motor with disc armature

The mathematical model of the disc motor is described by a set of electrical and mechanical differential equations in continuous time domain as follows :

\section{Armature electrical equation}

$V_{t}=E_{a}+I_{a}{ }^{*} R_{a}+L_{a}{ }^{*}{ } d_{a} / d t$

where

$$
E_{\mathrm{a}}=\mathrm{k}_{\mathrm{e}}{ }^{*} \omega_{\mathrm{m}}
$$

$\omega_{m}$ is the rotor speed ( $\mathrm{rad} / \mathrm{sec}$.)

$\mathrm{k}_{\mathrm{e}}$ is the back EMF constant. ( $/ \mathrm{rad} / \mathrm{sec}$.)

\section{Shaft mechanical equation :}

$T_{e}=T_{L}+B^{*} \omega_{m}+J^{*} d \omega_{m} / d t$ 
where :

$$
T_{e}=k_{t}{ } l_{a}
$$

$k_{t}$ is the torque constant (N.m/A)

$\mathrm{J}$ is the rotor inertia (Kg.m)

$B$ is the damping constant (N.m..sec./rad.)

$T_{L}$ is the load torque (N.m)

$\mathrm{I}_{\mathrm{a}}$ is the armature current $(\mathrm{A})$

$R_{a}$ is the armature resistance $(\Omega)$

$\mathrm{L}_{\mathrm{a}}$ is armature inductance $(\mathrm{H})$

The parameters of the disc type motor under consideration is given in appendix $\mathrm{A}$.

The load torque is assumed to be expressed as a function of the rotor speed as :

$$
T_{L}=\beta f\left[\omega_{m}(t)\right]
$$

where

$f\left[\omega_{m}(t)\right]$, is taken as :

$$
f\left[\omega_{m}(t)\right]=\quad \begin{array}{ll}
1 & \text { constant load } \\
\omega_{m}(t) & \text { linear load torque } \\
\omega_{m}^{2} & \text { quadratic load }
\end{array}
$$

and $\beta$ is a constant .

\section{3- system representation}

The pancake disc type DC motor drive system is shown in figure(3). It comprises the dc supply, a MOSFET type chopper and the fuzzy logic controller. In the digital simulation a simple PWM chopper is used to control the disc motor armature voltage .

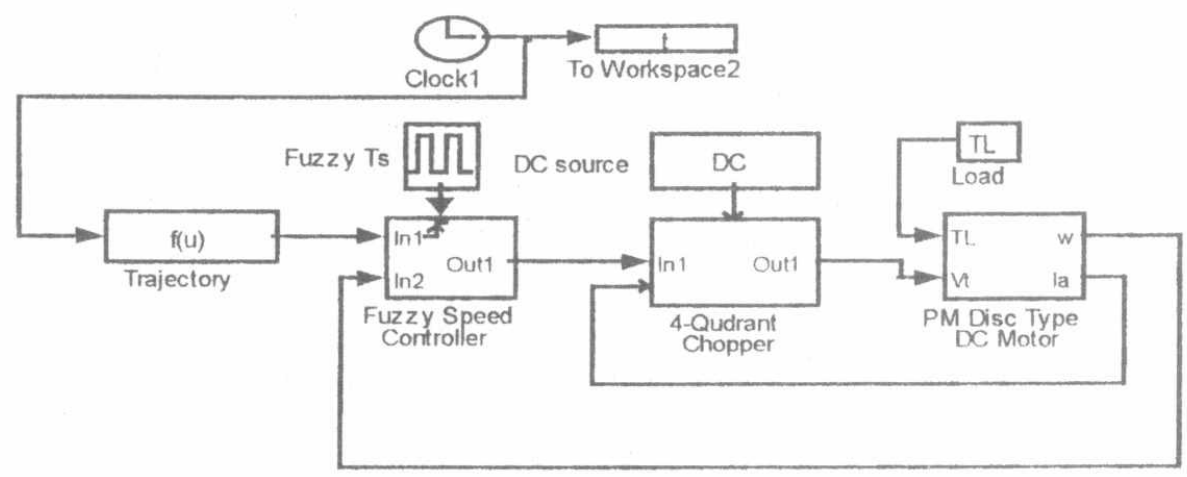

Fig.3. The functional block diagram representation of the proposed system

The desired trajectory of the rotor speed can be mathematically expressed as [4]: 
Proceedings of the $2^{\text {nd }}$ ICEENG Conference, 23-25 Nov. 1999

\begin{tabular}{|l|l|}
\hline $\mathrm{EF}^{\prime}-3$ & 5 \\
\hline
\end{tabular}

$\omega_{r}(k T)=10 \sin (2 \pi k T / 4)+16 \sin (2 \pi k T / 7), k T \in[0,20]$

where

$\omega_{\mathrm{r}}$ is reference speed ( $\mathrm{rad} / \mathrm{sec}$ )

$T$ is sampling time

$k$ is number of samples

\section{4- Fuzzy logic controller}

The fuzzy input vector comprises the following variables:

$$
\begin{aligned}
& e(k)=\omega_{r}-\omega_{m}(k) \\
& c e(k)=e(k)-e(k-1)
\end{aligned}
$$

where

$\mathrm{e}(\mathrm{k})$ is the error at $k^{\text {th }}$ sampling interval

$\mathrm{ce}(\mathrm{k})$ is the change of error at $k^{\text {th }}$ sampling interval

$\omega_{r}(k)$ is the reference speed at $k^{\text {th }}$ sampling interval

$\omega_{\mathrm{m}}(\mathrm{k})$ is the motor speed at $\mathrm{k}^{\text {th }}$ sampling interval

The output of the fuzzy controller is the control voltage and is defined as

$$
U_{c}(k)=U_{c}(k-1)+G U^{\star} \Delta U_{c}(k)
$$

where

$\Delta U_{c}(k)$ is the output signal of fuzzy controller at $k^{\text {th }}$ sampling interval

$\mathrm{GU}$ is the gain factor of the fuzzy controller

The gain factor GU can be adjusted to change the effective gain of the controller.

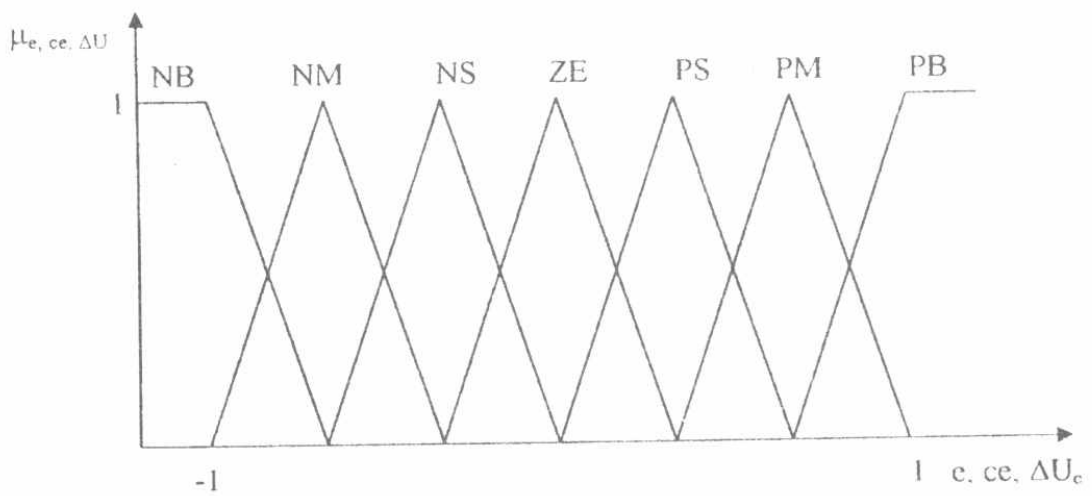

Fig. 4. Membership function for e, ce, $\Delta \mathrm{U}_{\mathrm{c}}$ 
The membership classes for the input variables $e(k)$ and $c e(k)$, and the output variable $\Delta U_{c}(k)$ are shown in figure (4). As shown in this figure, the universe of discourse(UOD) for both inputs and outputs is divided into seven fuzzy subsets: NB(Negative Big), NM(Negative Medium), NS(Negative Small) ,ZE(Zero) PS(Positive Small), PM(Positive Medium ), PB(Positive Big). The UOD cover a wide range of positive and negative change of the variables $e(k)$, $\mathrm{ce}(\mathrm{k})$ and $\mathrm{U}_{\mathrm{c}}\left((k)\right.$. The values of $\mathrm{e}(\mathrm{k}), \mathrm{ce}(\mathrm{k})$, and $\mathrm{U}_{c}(k)$ are normalized.

Figure(4) shows the shape and the arrangement of the membership function. It can be concluded that for any combination of $e(k)$ and $c e(k)$, a maximum of four rules are fired. Table (1) depicts the output decoding -rule which represent the output control signal $\Delta U_{c}(k)$ for all combinations of input variables.

Table 1. Rule base for the speed controller

\begin{tabular}{|c|c|c|c|c|c|c|c|}
\hline ce & $\mathrm{NB}$ & NM & NSt & $\mathrm{ZE}$ & PS & $\mathrm{PM}^{1}$ & $\mathrm{~PB}$ \\
\hline $\mathrm{NB}$ & NB & NB & NB & NB & NM & NS & $\mathrm{ZE}$ \\
\hline NM & NB & NB & NB & NM & NS & ZE & PS \\
\hline NS & NB & NB & NM & NS & $\mathrm{ZE}$ & PS & PM \\
\hline ZE & NB & NM & NS & $\mathrm{ZE}$ & PS & PM & PB \\
\hline PS & NM & NS & $\mathrm{ZE}$ & PS & PM & PB & PB \\
\hline $\mathrm{PM}$ & NS & $\mathrm{ZE}$ & PS & PM & PB & PB & PB \\
\hline $\mathrm{PB}$ & ZE & PS & PM & PB & PB & $\mathrm{PB}$ & PB \\
\hline
\end{tabular}

The rule assignment table is designed using human expertise to generate the output rule when knowing the input rule. For example

if $e(k)$ is NB and ce $(k)$ is NB then the output rule NB. This means that if $\omega_{m}(k)$ is greater than reference speed and the rate of change also increases then we need to decrease $V_{1}$ i.e $\Delta U_{c}$ take a negative value

The inference result of each rule consists of two parts, weighting factor $\left(u_{i}\right)$ of the individual rule, and the degree of change of control signal $\mu\left(u_{i}\right)$ according to the rule. The weighting factor $u_{i}$ is obtained by applying the minimum operation on the $\mu(\mathrm{e})$ and $\mu(\mathrm{ce})$. Defuzzification using center of area (COA) criterion selects the crispy output value corresponding to the center of gravity of the output membership function which is given by:

$$
\Delta U_{c}=\frac{\sum_{i=1}^{i=N} \mu\left(u_{i}\right)^{*} u_{i}}{\sum_{i=1}^{i=N} \mu\left(u_{i}\right)}
$$




\begin{tabular}{|l|l|}
\hline EP-3 & 7 \\
\hline
\end{tabular}

where $\mathrm{N}$ is the maximum number of effective rules.

\section{5-Simulation Results}

A pancake DC motor with disc shape is used at first in this study. The motor parameters are given in appendix A. The command trajectory is expressed in sample time in equation (5).

\section{Case(1): Disc Motor with FLC Under Varying Load Conditions}

\section{5-1 Constant Load Torque}

The motor in this case, is assumed to drive a load which is constant during the control period, while the rotor follows the speed trajectory as in figure (5). This control torque is given by:

$$
T_{L}=1.425 \mathrm{~N} \cdot \mathrm{m} \text { and } \beta=1.425
$$

Figure (6) presents the motor armature current during the control period, while figure (7) demonstrates the motor terminal voltage. Investigation of these figures reveals the following :

- The armature current is always positive during the control period, but the input motor voltage takes negative values when the rotor speed is negative.

- The armature starting current is about 3.87 A to overcome the load torque, while the input motor voltage at starting is $4.1 \mathrm{~V}$.

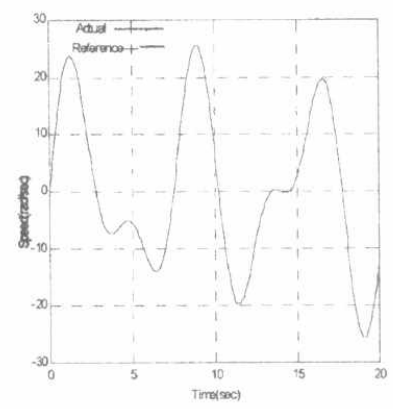

Fig.5. The speed trajectory

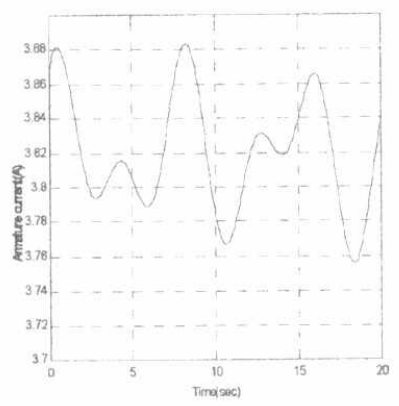

Fig.6. The armature current

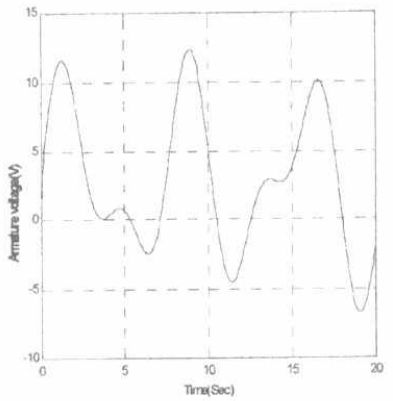

Fig.7. The armature voltage

\section{5-2 Linear Load}

In this case study the motor is assumed to drive a load for which the torque is proportional to the rotor speed, and is given by:

$T_{L}=.05 \omega_{m}$ N.m and $\beta=.05$ 


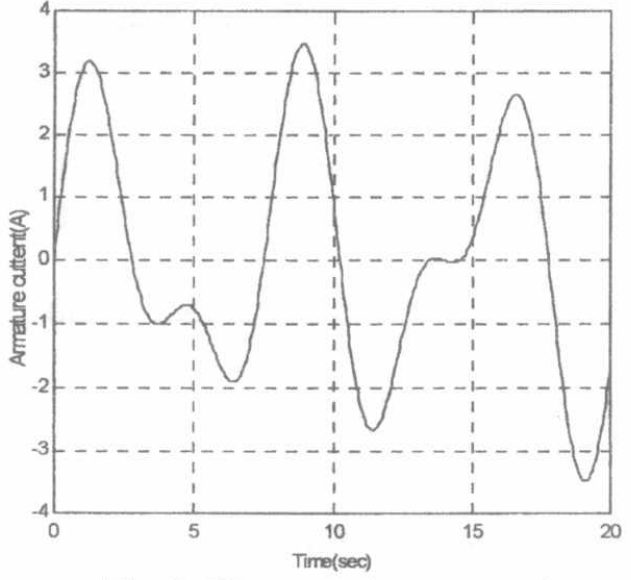

Fig.8. The armature current

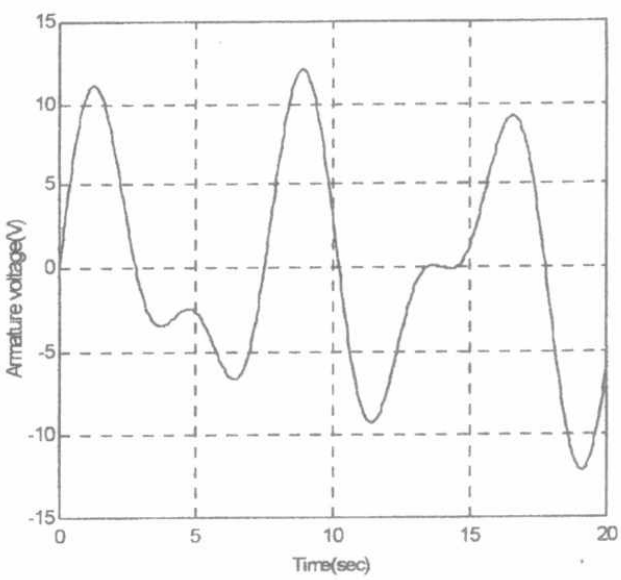

Fig.9. The armature voltage

The rotor speed trajectory will be the same as in figure (5), while the armature current variation during the control period is given in figure (8). Figure (9) gives the input armature voltage during the same period. Examining these two graphs illustrates that:

- The armature current as well as the motor input voltage follows exactly the rotor speed trajectory, i.e., at starting, $\omega_{m}=0$, the armature current and the input voltage are also zero. Also, when the rotor speed is negative, the armature current and the input voltage are also negative.

- The maximum positive current for this load is less than the maximum positive current for constant load.

\section{5-3 Quadratic Load}

The load torque in this section varies as the square of the rotor speed, and is given by :

$\mathrm{T}=.0008 \omega_{\mathrm{m}}^{2} \mathrm{~N} \cdot \mathrm{m}$ and $\beta=.0008$

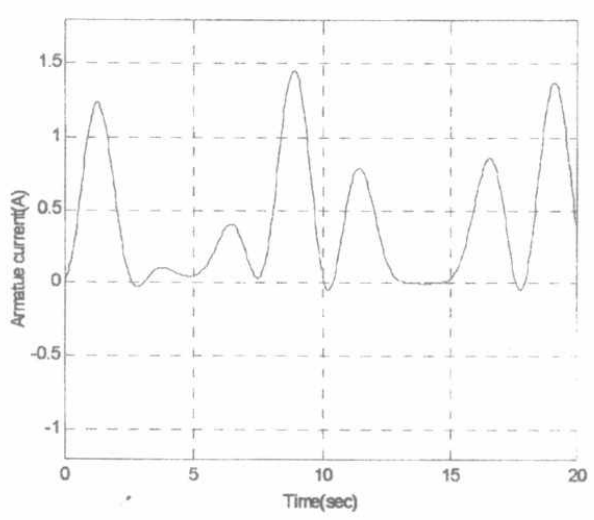

Fig.10. The armature current

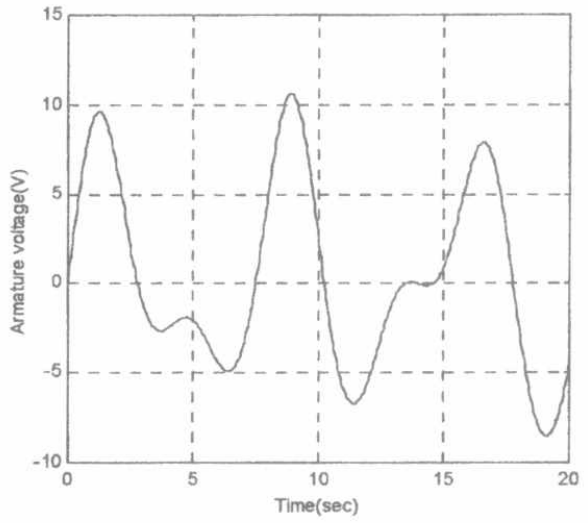

Fig.11. The armature voltage 
This torque is positive during the whole control period. Figures (10) and (11) present the armature current and the input armature voltage respectively during the control period. It is obvious from examination of these graphs that

- The motor armature current is always positive during the control period, since the load torque is always positive and the field current is assumed to be constant during this period.

- The maximum current is reduced considerably and has the smallest value among the three load torques.

- The rotor speed follows the command trajectory as in figure (4).

\section{Case(2): Disc Motor with PI Under Varying Load Conditions}

In both cases the rotor speed follows the reference trajectory, however the speed error with PI controller is greater than that with FLC. Figure (12) and (13) illustrate the two cases.

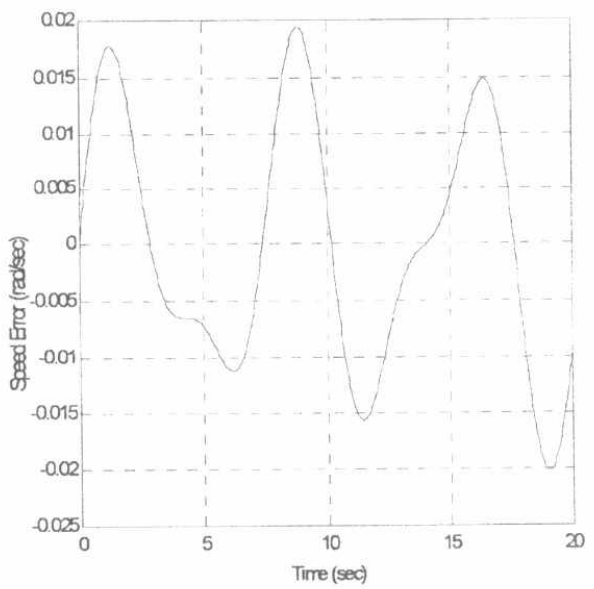

Fig.12. The speed error With FLC

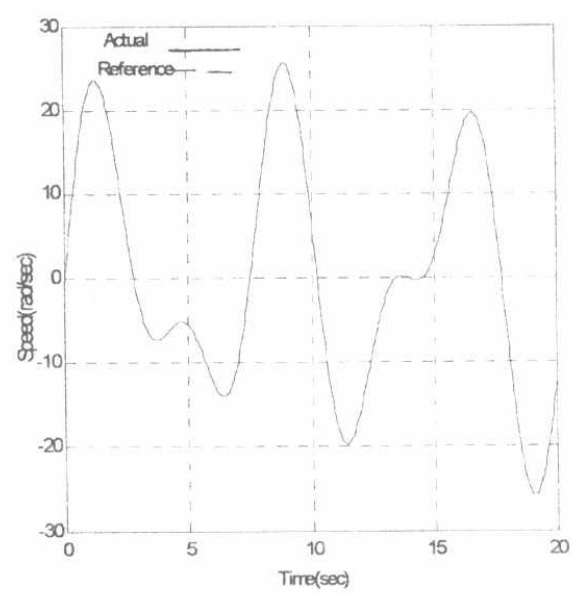

Fig. 14. The speed trajectory With FLC

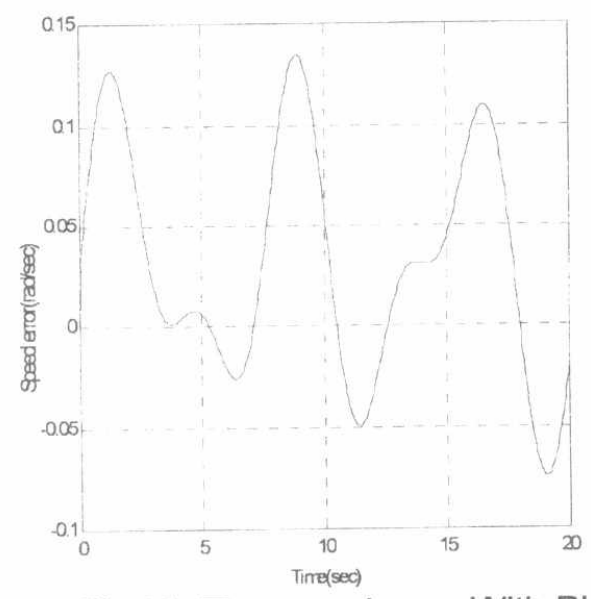

Fig.13. The speed error With PI

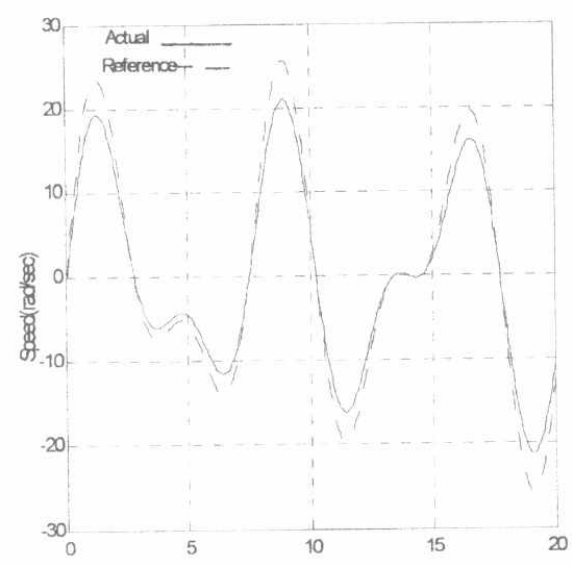

Fig.15. The speed trajectory With PI 


\section{Case(3): Replacement of DC Motor}

The disc type DC motor is replaced with separately exited DC motor with the same loading conditions as those motors of $[1,4,7,9]$. It is obvious from investigating of figures (14) and (15) that the rotor speed with fast FLC tracks the command trajectory as that for a disc motor, however the response with $\mathrm{PI}$ controller is not satisfactory. Therefore, the parameters of $\mathrm{PI}$ controller has to be retuned.

\section{Conclusion}

An easy and simple fuzzy logic speed control strategy is presented in this paper. This control strategy ensures excellent speed reference tracking of PM DC motor with disc type and separately excited DC motor used on robotics, actuation, and guided manipulation. The simulation study proves that, the fuzzy logic controller is effective in speed tracking of DC motor under varying motors and load conditions compared with the conventional Pl-controller.

\section{References:}

[1] H.Nehrir and F.Fatehi, "Tracking Control of DC Motors Via Input-Output Linearization, "Electric Machines and Power Systems Volume 24,No.3,1996,pp.237-247

[2] Hussein F.Soliman, M.A.LBadr and A.M.Sharaf, "Fuzzy Logic Controller for DC Series Motor Chopper Fed Locomotive-Drive", ICECS'97, December 15-18, 1997, Cairo Egypt.

[3] Dr.Gehard Henneberger, Dr. Helmut Harer, Dr. Siegfried Schustek and Dr.Ludger verstege, "A New Range of DC and AC Pancake Motors", International Conference on Electrical Machines,8-10 September,1986, Jermany, Part(3), pp.916-919.

[4] S.Weerasooriya and M.A.El-Sharkawi,"Identification and Control of DC Motor Using Back-Propagation neural networks", IEEE Trans. on Energy Conversion Volum 6,No.4,December 1991,pp.663-669.

[5] S.Weerasooriya and M.A.El-Sharkawi ,"Adaptive tacking Control for High Performance DC Drives", IEEE Trans on Energy Conversion, Volume 4,No.3,September 1989,pp.502-508.

[6] M.A El-Sharkawi and S. Weerasooriya,"Development and Implementation of Self-Tuning Tracking Controller for DC motors," IEEE Trans. on Energy Conversion, Volume5,No.4,March 1990,pp.122-128.

[7] S.A.Soliman,"'Digital Control of A High-Performance Separately excited DC Motor", International Journal of Power and Energy Systems, Volume 16,No.2,1996,pp102-106.

[8] I.H. Khalifa,M.H.Saleh and A.H.Elassal,"A Fuzzy Logic Speed Control of a DC Shunt Motor", Fifth International middle East Power Conference MEPCON'97,Alexandria, Egypt,Jun. 4-6,1997,pp.76-81. 
[9] A.M.M. Hussein,Mohab Hallouda and K.A.El-Metwailly, "Application of Fuzzy Logic in The Speed Control of DC Motors", Al-Azhar Engineering Fourth International Conference, December16-19,1995,pp. 298-309.

[10] Hussein F.Soliman, A A. Atia and M.A. Lbadr,"A PD Fuzzy Logic Controller for Electric Motor Driving the Astronomical Telescope", Sixth MEPCON'98,Mansoura,Egypt, Dec. 15-17,1998.

[11] R.Mostafa,A.El-Kosy and U.Abo-Zayed, "Simulation of a Fuzzy Controlled Disc Type DC Motor Drive Fed From Quasiresonant Converter Using SIMULINK", Proc. of the $9^{\text {th }}$ Inter. Conf. On Computer Theory and Applications,28-30 August 1999,Alex.-Egypt,pp324-333

[12] Timothy J.Malony, "Modern Industrial Electronics ", Prentice Hill, 1996.

[13] Dr. Gehard Henneberger,"Servo Drives for Machine Tools and Robotics", International Conference on Electrical Machines,8-10 September, 1986, Part(1),pp. 21-33.

[14] E.V.Armensky and G.B.Falk, "Fractional Horse Power Electrical Machines", Mir Publishers, 1985.

[15] A.E. Fitzegerald, Charles Kingsley and Jr. Stephen D. Umans," Electric Machinery", Mc Graw-Hill, Inc.,1990.

Appendix A: The parameters of the pancake DC motor with disc shape are given in the following table

\begin{tabular}{|l|l|l|}
\hline$R_{a}$ & 0.74 & $\Omega$ \\
\hline$L_{a}$ & 0.000085 & $H$ \\
\hline$K_{t}$ & 0.3728 & N.m/A \\
\hline$K_{0}$ & 0.3726 & $\mathrm{v} / \mathrm{rad} / \mathrm{sec}$ \\
\hline $\mathrm{J}$ & 5.0093 & $\mathrm{Kg} \cdot \mathrm{m}^{2}$ \\
\hline$B$ & 6.0004 & N.m.sec./rad \\
\hline
\end{tabular}

The Parameters of disc motor 